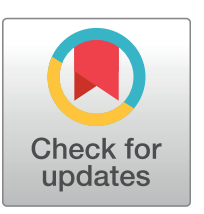

\section{G openaccess}

Citation: Si H, Genna B, Zhuang X, Wang J, Burenbatu B, Feng Q, et al. (2020) DaHuangWan targets EGF signaling to inhibit the proliferation of hepatoma cells. PLOS ONE 15(4): e0231466. https://doi.org/10.1371/journal.pone.0231466

Editor: Salvatore V. Pizzo, Duke University School of Medicine, UNITED STATES

Received: December 25, 2019

Accepted: March 24, 2020

Published: April 16, 2020

Peer Review History: PLOS recognizes the benefits of transparency in the peer review process; therefore, we enable the publication of all of the content of peer review and author responses alongside final, published articles. The editorial history of this article is available here: https://doi.org/10.1371/journal.pone.0231466

Copyright: @ 2020 Si et al. This is an open access article distributed under the terms of the Creative Commons Attribution License, which permits unrestricted use, distribution, and reproduction in any medium, provided the original author and source are credited.

Data Availability Statement: All relevant data are within the paper and its Supporting Information files.

Funding: This work was supported by grants from Natural Science Foundation of Inner Mongolia (NO.

RESEARCH ARTICLE

\title{
DaHuangWan targets EGF signaling to inhibit the proliferation of hepatoma cells
}

$\mathrm{Ha} \mathrm{Si}^{1,2,3 \odot}, \mathrm{Ba} \mathrm{Genna}^{2 \odot}$, Xiangjin Zhuang $^{3 \ddagger}$, Jing Wang ${ }^{3,4 \ddagger}$ B. Burenbatu ${ }^{1 *}$, Qiyu Feng ${ }^{3 *}$ Hongyang Wang ${ }^{3 *}$

1 Affiliated Hospital of Inner Mongolia University for the Nationalities, Tongliao, Inner Mongolia, China, 2 Inner Mongolia University for the Nationalities, Tongliao, Inner Mongolia, China, 3 National Center for Liver Cancer, Eastern Hepatobiliary Surgery Hospital/Institute, the Second Military Medical University, Shanghai, China, 4 Division of Life Sciences and Medicine, Cancer Research Center, The First Affiliated Hospital of USTC, University of Science and Technology of China, Hefei, Anhui, China

ه These authors contributed equally to this work.

$\ddagger$ These authors also contributed equally to this work.

* qiyu@ icloud.com (QF); hywangk@ vip.sina.com (HW); brbt2013@163.com (BB)

\section{Abstract}

DaHuangWan (DHW) is a traditional herbal medicine used by Mongolian to treat liver cancer for many years. Clinical application of the drug has been shown to help control tumor progression, prolong survival and improve quality of life. However, the underlying mechanisms and side effects of this drug remain unclear, which greatly limits the clinical application and further optimization of DHW. In this study, we found that DHW inhibits the proliferation of hepatoma cells by modulating the epithelial growth factor (EGF) signaling pathway. Berberine and Costunolide are the main active ingredients in DHW. Interestingly, the combination of Berberine and Costunolide has a dramatic synergistic effect on inhibiting the proliferation of hepatoma cells. Neither Berberine nor Costunolide directly block EGFR phosphorylation. Berberine promotes endocytosis of activated EGFR, while as Costunolide increases ubiquitination of EGFR and reduces EGFR recycling to cell membrane distribution, thereby inhibiting EGF signaling. Berberine and Costunolide target two different steps in regulating the EGF signaling, which explains the synergistic anti-cancer effect of DHW. Since Berberine and Costunolide do not directly target EGFR phosphorylation, DHW could be a supplementary medicine to tyrosine kinase inhibitors in cancer therapy.

\section{Introduction}

Liver cancer is one of the most common and fatal malignant tumors, with 5-year survival rate estimated at $20 \%-30 \%$. According to GLOBOCAN, around 782,000 people were estimated to die of the disease in 2018, making it the fourth leading cause of cancer death worldwide [1]. In recent years, the incidence of primary liver cancer has risen dramatically, and hepatocellular carcinoma (HCC), the predominate pathological type of primary liver cancer, registered the highest and the most rapid rate of increase in the recent period of time [2]. Therefore, it is vital to find new drugs and strategies for HCC treatment. 
2018MS08038, to HS) and National Natural Science foundation of China (NSFC, 81773112, to QF).

Competing interests: The authors declare no potential conflicts of interest.
DaHuangWan (DHW), a traditional herbal formula, consists of two herbal ingredients, Coptidis Rhizoma and Aucklandia lappa Decne, with a ratio of 1:1 (w/w) [3]. It has been used clinically in Mongolia for many years to treat gastroenterological disorders and HCC. However, there are no well-controlled scientific experiments to verify the validity of DHW prescription, and the underlying mechanism of the drug remains unclear, which greatly limits the clinical application and further optimization of DHW.

Traditional herbs are usually used in combination. Herb pair, a basic unit in multi-herbal formula, consists of two single herbs and usually has better pharmacological effects than using these herbs alone [4]. Coptidis Rhizoma (HuangLian) and Aucklandia lappa Decne are commonly used as paired herbal medicine for cancer treatment. According to chinese traditional medical literature, Coptidis Rhizoma is a widely used traditional chinese herb that eliminates 'heat' and 'toxicity'. The anti-cancer effects of Coptidis Rhizoma may be due to these traditional medical properties of Coptidis Rhizoma [5]. It has been reported that Coptidis Rhizoma extract and its active ingredient, Berberine, has an anti-tumor effect on various human cancers [5]. Coptidis Rhizoma extract inhibits the migration and invasion of HCC cells by down-regulating the RHO/ ROCK signaling pathway [6]. Berberine induces death of human hepatoma cells in vitro by down-regulating CD147 [7]. Aucklandia lappa Decne has been used in China for the treatment of asthma, anorexia, nausea, ulcers and stomach problems for many years $[8,9]$. It is also considered as an anti-cancer herb. Recent studies have shown that the ethanol extract of Aucklandia lappa Decne has anti-cancer effect on prostate cancer, oral cancer, breast cancer, and cervical cancer [10-12]. In addition to its anti-tumor chemo-preventive effect, Costunolide also has anti-cancer activity against various cancer cells such as lung cancer, breast cancer, and liver cancer, and can inhibit the invasion and metastasis of cancer cells [1319]. Although Berberine and Costunolide have decent anti-cancer activity, it is not clear whether Berberine and Costunolide are key functional components of DHW, and the benefits of this combination for liver cancer treatment. In this study, we examined the effect of DHW on hepatoma cell proliferation and further explored its underlying mechanisms.

Epidermal growth factor (EGF) signaling is a core signaling pathway that regulates cell proliferation. Epidermal growth factor receptor (EGFR) amplification and its abnormal activity are tightly linked to the occurrence and development of various malignant tumors including liver cancer $[20,21]$. Therefore, key molecules in EGFR signaling are considered to be important oncogenic factors and critical therapeutic targets. For example, Cetuximab, a chimeric (mouse/human) monoclonal antibody against EGFR, was approved by FDA in 2004 and by CHMP in 2008 in combination with platinum-based therapy for the treatment of patients with squamous cell carcinoma of the head and neck with metastatic disease, and in combination with radiation therapy for locally advanced cancer [22]. Gefitinib, a small molecular EGFR inhibitor, is approved for the treatment of patients with non-small cell lung cancer (NSCLC) after failure of both platinum-based or docetaxel chemotherapies [22,23].

In addition to EGFR phosphorylation, homeostasis of EGFR is also critical for EGF signaling. This homeostasis is maintained by modulating endocytosis, degradation and recycling of the EGFR [24-26]. When EGFR is activated, endocytosis occurs through two pathways: clathrin-dependent and clathrin-independent. Typically, EGFR binds to a ligand and is engulfed by primary endocytosis, converting from a membrane distribution to an intracytoplasmic vesicle distribution. After signaling to downstream molecules, a portion of the EGFR can escape from primary endocytosis and be recycled to the membrane to continue binding to the ligand. For EGFR that cannot be separated from primary endocytosis, the ubiquitin-protease system will be activated to degrade EGFR when primary endocytic vesicles grow into secondary vesicles and bind to lysosomes [27,28]. EGFR homeostasis is maintained by receptor internalization processes, including endocytosis, ubiquitination and degradation, leading to well- 
controlled activation of downstream signaling cascades. The ubiquitination of EGFR is a key regulatory node of this process and is then critical for the output of EGF signaling.

In the present study, we demonstrate that DHW inhibits the proliferation of hepatoma cells by modulating the EGF signaling pathway. In addition, the two active ingredients of DHW, Berberine and Costunolide have a dramatic synergistic effect on inhibiting the proliferation of liver cancer cells. This synergistic effect can be attributed in part to Berberine promoting endocytosis of activated EGFR, while Costunolide increases ubiquitination of EGFR and reduces EGFR recycling to cell membrane distribution.

\section{Materials and methods}

\section{Chemicals and reagents}

Cell cycle and apoptosis analysis kit, EdUrd Cell Proliferation Kit with Alexa Fluor 488 and Anti-ubiquitin antibody were purchased from Beyotime (Nanjing, China); Anti-EGFR, Anti Phospho-EGFR and $\beta$-actin antibodies were from Abcam(Cambridge, UK); The herb plant materials of Coptidis Rhizoma and Aucklandia lappa Decne were purchased from TongRenTang pharmacy (BeiJing, China); Berberine and Costunolide with the purity of $98.8 \%$ used as the positive control was obtained from food and drug testing institute (Bei Jing, China).

\section{Preparation of DHW extracts and determination of its active constituents}

According to the proportion of the prescriptions of DHW, weighed the same amount of each medicinal herbs and crushed them. $500 \mathrm{~g}$ of the mixed drug powder was taken, and 8 times of $75 \%$ ethanol was added there to, and the mixture was heated under reflux for 3 times for 1.5 hrs, filtered, and the filtrate was combined. Ethanol was recovered by evaporation on a rotary evaporator and dried in a vacuum rotary concentrator.

The sample was analyzed using a Shimadzu Prominence LC-20A series HPLC apparatus (Shimadzu Co., Kyoto, Japan) equipped with auto sample injector (SIL-20AC) and PDA photo diode array detector (SPD-M20A). Berberine was separated by water and acetonitrile (50:50, $\mathrm{v} / \mathrm{v}$ ) at a flow rate of $1.0 \mathrm{ml} / \mathrm{min}$. The column used for Berberine was the Hypersil ODS2 (100 $\mathrm{mm} \times 4.6 \mathrm{~mm}, 5 \mu \mathrm{m}$ particle size), and Berberine was detected at $345 \mathrm{~nm}$. The mobile phase for Costunolide was comprised of acetonitrile/water $(65: 35, \mathrm{v} / \mathrm{v})$. The solvent flow rate was 1.0 $\mathrm{ml} / \mathrm{min}$ and Costunolide was detected at $225 \mathrm{~nm}$. Contents of Berberine and Costunolide in DHW extracts were determined by referring to the calibration curve established by running standard at varying concentrations under the same conditions.

\section{Cell lines and cell culture}

Human hepatocellular carcinoma cell lines (PLC/PRF/5, SMMC-7721, Hur-7, HCC-LM3 and HepG2) and QSG-7701 hepatocyte cell line were obtained from the Shang Hai Cell Biology Institute of Chinese Academy of Science (Shanghai, China). The cells were cultured in a medium containing $10 \%$ FBS and RPMI 1640, and changed every 2 days.

\section{Cell viability assay}

All kinds of cancer cells were seeded in 96-well cell culture plates at the concentration of $2 \times 10^{3}$ $\sim 5 \times 10^{3}$ cells per well. After incubation overnight, the medium was removed and replaced with fresh medium with or without DHW extract. Cell density was measured on day 1,2 , and 3 by using the3-(4,5-dimethylthiazol-2yl)-2,5-diphenyltetrazolium bromide (MTT) following the manufacturer's instructions. The absorbance of converted dye is measured at the wavelength 
of $490 \mathrm{~nm}$ and the absorbance is directly proportional to cell viability. All experiments were repeated at least three times.

\section{Analysis of cell cycle and apoptosis by flow cytometry}

To determine the cell cycle, $2 \times 10^{6}$ cells/well were seeded in 6-well cell culture plates and treated with DWH at a final concentration of $40 \mu \mathrm{g} / \mathrm{ml}$. After $48 \mathrm{hrs}$ treatment, both floating and trypsinized adherent cells were collected and fixed with 70\% ethanol. After fixation, the cells were washed with ice PBS and stained with propidium iodide (PI) for 30 mins under subdued light. Stained cells were analyzed using BD FACS Calibur and CellQuest software (BD LSRFortessa, USA). For cell apoptosis, PLC/PRF/5 cells were indicated, collected, and stained with Houchst33342 and PI as recommended by the manufacturer. Apoptotic cells were detected by flow cytometry, and the extent of apoptosis was calculated with FlowJo software (version 7.6.1).

\section{EdUrd incorporation assay}

To determine EDUrd incorporation, PLC/PRF/5 cells were seeded in sterile chamber-well slides. After $24 \mathrm{hrs}$ of plating, incubation was continued for another $48 \mathrm{hrs}$ in absence (control) or presence of different testing agents as described in the legends to the figures. At the end of the $48 \mathrm{hrs}$ incubation period, added to the medium along with EDUrd $(20 \mu \mathrm{M})$. After $2 \mathrm{hrs,}$ the percentage of EDUrd positive cells were determined examined a fluorescence microscope.

\section{Immunoprecipitation and Western blot analysis}

After drug treatment, PLC/PRF/5 cells were lysed with NP-40 buffer and the protein concentration of was determined by Bradford protein assay kit (thermo fisher). For Immunoprecipitation, equal amount $(0.2 \sim 1 \mathrm{mg})$ of total protein samples were incubated with EGFR antibodies at $4^{\circ} \mathrm{C}$ overnight with gentle mixing, followed by the addition of $20 \mu \mathrm{l}$ of protein A/ $\mathrm{G}$ beads and continued incubation for another $2 \mathrm{hrs}$. The beads were pelleted via centrifugation at $2500 \mathrm{rpm}$ for 3 mins and washed five times with NP-40 buffer. The precipitated proteins were eluted in $40 \mu \mathrm{l}$ of lysate sample buffer. For Western blot analysis, the proteins were subjected to 4 15\% SDS-PAGE and transferred to nitrocellulose membranes (Amersham Biosciences, Buckinghamshire, UK). The membranes were blocked with 5\% milk and were incubated with the indicated primary antibodies. Odyssey infrared fluorescence scanning imaging system can read the film and conduct semi-quantitative analysis.

\section{Cell surface protein biotinylation and internalization assay}

Cell surface protein was isolated using Pierce Cell Surface Protein Isolation Kit (Pierce, Rockford, IL). Briefly, after drug treatment, PLC/PRF/5 cells were washed three and suspended in ice-cold PBS ( $\mathrm{pH}$ 8.0). Biotinylation was performed by incubating cells in PBS containing EZlink Sulfo-NHS-SS-biotin for 30 mins. Cells were subsequently washed three times with icecold PBS to remove unreacted reagent. Labelled cells were lysed and cell surface proteins were immunoprecipitated with avidin resin and analyzed by immunoblot with EGFR antibody.

EGFR internalization was performed using Pierce Cell Surface Protein Isolation Kit as well. Briefly, the proteins on the cells surface were first Biotinylated with reducible Sulfo-NHS-SSbiotin at $4{ }^{\circ} \mathrm{C}$. The biotin reaction was quenched for 10 mins with $0.1 \mathrm{M}$ lysine (Thermo Fisher). After they were washed with PBS, cells were added to pre-warmed culture medium (without or with the different treatment compounds) and incubated at $37^{\circ} \mathrm{C}$ for the indicated time. After stimulation with EGF $10 \mathrm{ng} / \mathrm{ml}$, cell surface biotin was removed by treatment $(2 \times 20 \mathrm{mins})$ at 4 
${ }^{\circ} \mathrm{C}$ with sodium 2-mercaptoethanesulphonate (MesNa). The internalized proteins were immunoprecipitated with avidin resin and analyzed by immunoblot with EGFR antibody.

\section{Statistical analysis}

All statistical analyses were performed using Graph Pad Prism. The data shown represents the mean \pm SD from at least three independent experiments. Student's t-test was used to compare two groups. ANOVA (One-way analysis of variance) used to analyze statistical differences between groups under different conditions. $\mathrm{P}$ values $<0.05$ is considered to have significance.

\section{Result}

\section{DHW extract inhibits the proliferation of hepatoma cells}

DHW is a traditional herbal medicine used in Mongolia for the treatment of liver cancer for many years. The drug is claimed to have a clinically inhibitory effect on tumor progression. But so far, there are no well-controlled scientific experiments to verify the validity of DHW prescription. In this study, we first prepared DHW extract by refluxing DHW in ethanol. Then, we examined the effects of DHW extract on the growth of various liver cancer cells. $\mathrm{PLC} / \mathrm{PRF} / 5$ hepatoma cells or QSG-7701 human hepatocytes were seeded in 12-well plates for $24 \mathrm{hrs}$ and then these cells were treated with DHW extract. The number of cells was counted after 2, 4, and 6 days. We found that DHW extract significantly inhibited the growth of PLC/ PRF/5 cell, while it had limited effect on the growth of QSG-7701 cells (Fig 1A and 1B). We then further quantified the inhibitory effect of DHW extract on various liver cancer cells. SMMC-7721, Hur7, HepG2, and LM3 cells were seeded in 96-well plates for $24 \mathrm{hrs}$ and then treated with different dose of DHW extract $(20 \sim 500 \mu \mathrm{g} / \mathrm{ml})$. Cell viability was measured after 24, 48 and $72 \mathrm{hrs}$. The $\mathrm{IC}_{50}$ values of these liver cancer cells was calculated (Table 1). As shown in Fig 1C, DHW extract inhibited the growth of SMMC-7721, HepG2, Hur7, and LM3 cells in a dose-and time-dependent manner, and these cells have different sensitivities against DHW extract. The effect of DHW on the QSG-7701 human hepatocytes was limited (Fig 1B), indicating that the inhibition of DHW on the growth of various liver cancer cell lines should not be derived from cytotoxicity.

To determine whether DHW inhibits the growth of hepatoma cells by blocking the cell cycle or inducing apoptosis, we examined the cell cycle distribution and apoptosis of PLC/ $\mathrm{PRF} / 5$ cells after DHW treatment. Among the cell lines we examined, $\mathrm{PLC} / \mathrm{PRF} / 5$ cell is the most sensitive to DHW treatment ( $\mathrm{IC}_{50}$ value: $43.29 \pm 1.34 \mu \mathrm{g} / \mathrm{ml}$ for $72 \mathrm{hrs}$ treatment, Table 1). PLC/PRF/ 5 cells were cultured for $24 \mathrm{hrs}$, then treated with $40 \mu \mathrm{g} / \mathrm{ml}$ DHW extract for $48 \mathrm{hrs}$, and analyzed by flow cytometry. We found that the number of cells arrested in the G0/G1 phase increased by $20 \%$, while the proportion of cells in the S phase decreased sharply by $16 \%$ (Fig 1D). As shown in Fig 1E, the apoptosis of PLC/PRF/5 cells increased only slightly from $2.5 \pm 0.4 \%$ to $3.8 \pm 0.7 \%$ after $48 \mathrm{hrs}$ of treatment with $40 \mu \mathrm{g} / \mathrm{ml}$ DHW extract. This result indicates that DHW does not inhibit PLC/PRF/5 cells by inducing apoptosis. With EDUrd incorporation assay, we further confirmed that DHW extract significantly inhibited DNA synthesis in PLC/PRF/5 cells (Fig 1F). The result in Fig 1 demonstrates that DHW extract inhibits the proliferation of hepatoma cells.

\section{Berberine and Costunolide, two key active components in DHW, synergistically inhibit hepatoma cell proliferation}

DHW is a traditional herbal medicine consisting of Coptidis Rhizoma and Aucklandia lappa Decne, with a ratio of 1:1 (w/w). It is well known that Berberine and Costunolide are the main 
A.

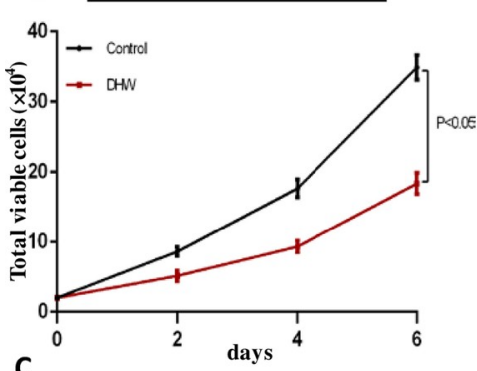

C.

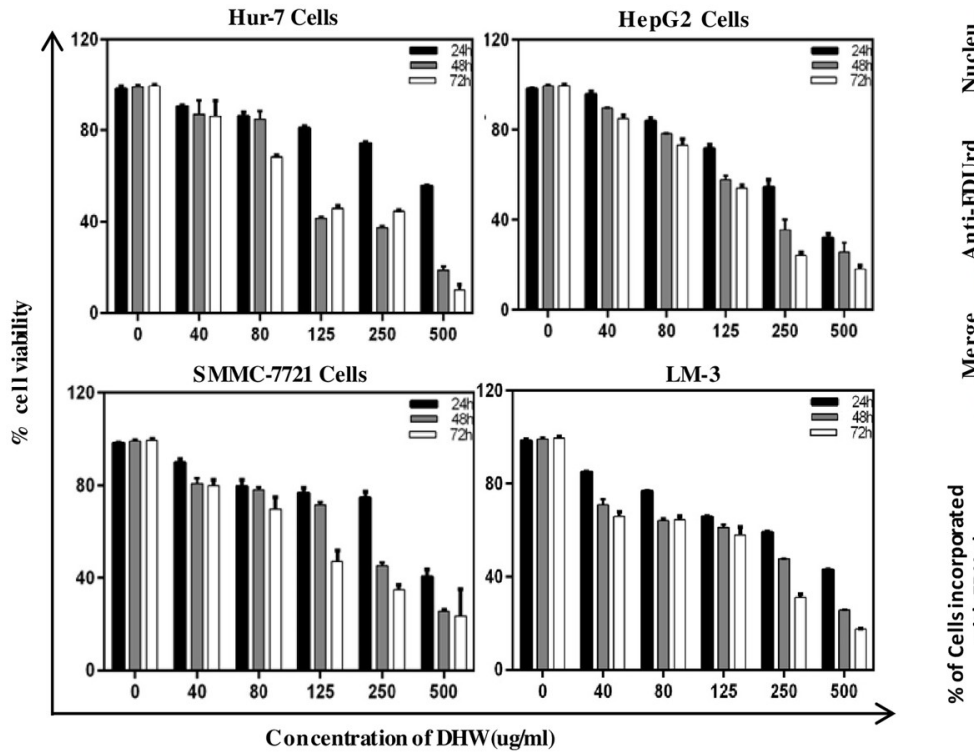

D.

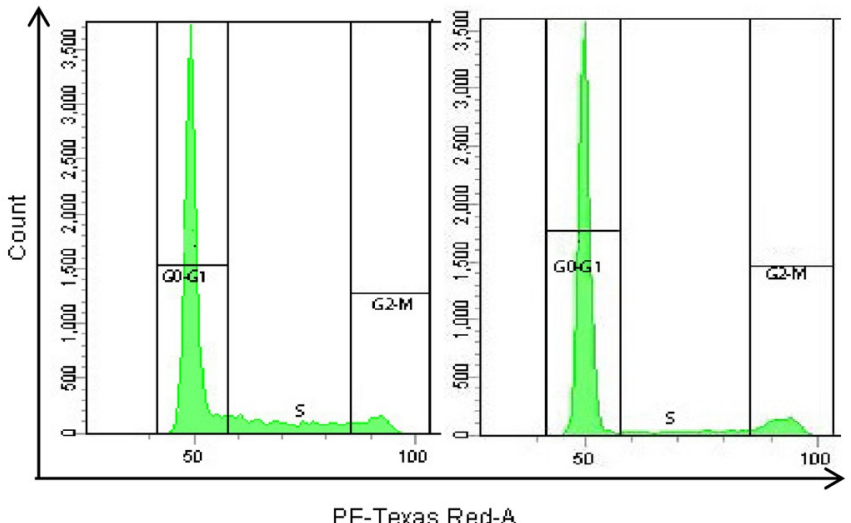

B.

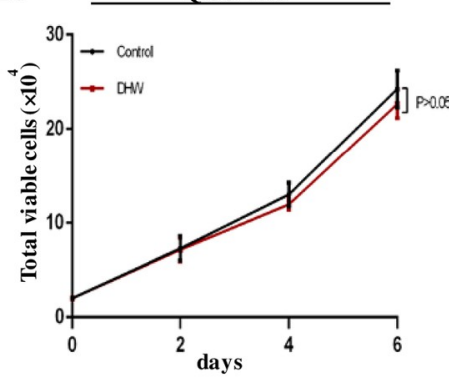

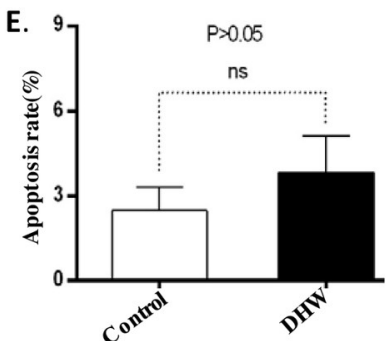

F.
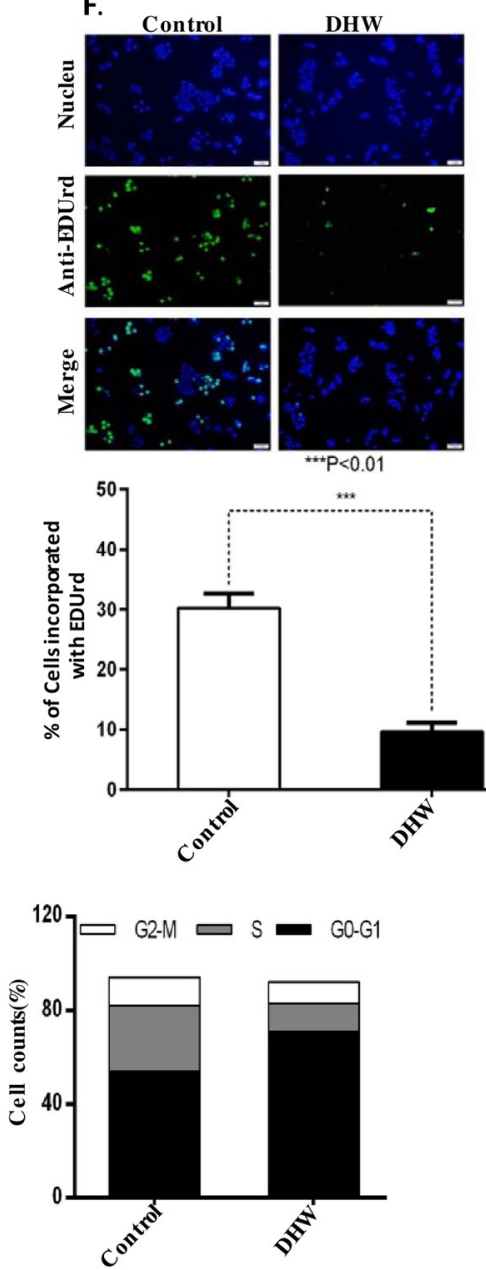

Fig 1. PLC/PRF/5 (A), and QSG-7701 (B), cells $\left(2 \times 10^{4}\right)$ were seeded in 12 -well plates and cultured in DMEM treated with DHW $(40 \mu \mathrm{g} / \mathrm{ml})$. The number of cells was counted at the indicated times. C, Cell viability determined by MTT assay. Liver cancer cells were treated with different concentrations of DHW extract for 24,48 , and $72 \mathrm{hrs}$, and cell viability was determined by MTT. D, DHW extract induces G0/G1 arrest of PLC/PRF/5 cell line. Cells were treated without or with $40 \mu \mathrm{g} / \mathrm{ml} \mathrm{DHW}$ extract for $48 \mathrm{hrs}$ and then the cell cycle population was measured by flow cytometry. E, Apoptosis in PLC/PRF/5 cells determined by flow cytometry. Cells were treated without or with $40 \mu \mathrm{g} / \mathrm{ml}$ DHW extract for $48 \mathrm{hrs}$, and then apoptosis was measured by flow cytometric analysis of cells stained with Houchest3324 and PI. The percentages of Houchest3324 or/and PIpositive cells are indicated. F, PLC/PRF/5 Cells were treated with DHW extract for 48 hrs before they were assayed for EdUrd incorporation. Data are presented as the mean \pm SD of values from triplicate experiments.

https://doi.org/10.1371/journal.pone.0231466.g001 
Table 1. IC $_{50}$ values of DHW extract on different cell lines.

\begin{tabular}{c|c|c|c}
\hline \multirow{2}{*}{ Cell line } & \multicolumn{3}{|c}{ IC $_{\mathbf{5 0}}$ values $(\boldsymbol{\mu g} / \mathbf{m l})$} \\
\cline { 2 - 4 } & $\mathbf{2 4 h}$ & $\mathbf{4 8 h}$ & $\mathbf{7 2 h}$ \\
\hline PLC/PRF/5 & $213.10 \pm 1.07$ & $68.95 \pm 1.42$ & $43.29 \pm 1.34$ \\
\hline HepG2 & $376.30 \pm 0.78$ & $178.90 \pm 0.98$ & $119.90 \pm 0.84$ \\
\hline LM3 & $438.60 \pm 0.89$ & $150.90 \pm 1.06$ & $128.80 \pm 1.11$ \\
\hline Hur7 & $338.50 \pm 1.06$. & $212.80 \pm 1.05$ & $171.50 \pm 0.95$ \\
\hline SMMC7721 & $341.20 \pm 1.00$ & $220.70 \pm 1.25$ & $147.14 \pm 1.17$ \\
\hline
\end{tabular}

https://doi.org/10.1371/journal.pone.0231466.t001

bioactive components of Coptidis Rhizoma and Aucklandia lappa Decne [29]. Therefore, we first quantified the content of Berberine (5.6\%) and Costunolide (1.2\%) in DHW extract by HPLC (Fig $2 \mathrm{~A}$ and $2 \mathrm{~B})$. Then, pure Berberine $(2.5 \mu \mathrm{g} / \mathrm{ml})$ and Costunolide $(0.5 \mu \mathrm{g} / \mathrm{ml})$ were mixed according the abundance determined above to form a Berberine-Costunolide mixture (named as BC mix here after). PLC/PRF/5 cells were incubated with Berberine $(2.5 \mu \mathrm{g} / \mathrm{ml})$, Costunolide $(0.5 \mu \mathrm{g} / \mathrm{ml})$, this BC mix, or $40 \mu \mathrm{g} / \mathrm{ml}$ DHW extract for $48 \mathrm{hrs}$. EDUrd incorporation assay was then performed. As shown in Fig 2C, both Berberine and Costunolide inhibited the proliferation of PLC/PRF/5 cells. The BC mix and DHW extract had similar inhibitory effects on PLC/PRF/5 cells (Fig 2C). The inhibitory effect of BC mixture or DHW extract on $\mathrm{PLC} / \mathrm{PRF} / 5$ cells was better than that of Berberine or Costunolide alone (Fig 2C). The results indicate that Berberine and Costunolide are indeed anti-cancer active ingredients of DHW, and the combination of Berberine and Costunolide is sufficient to mimic the inhibition of DHW on PLC/PRF/5 cells.

In these experiments (Fig 2C), we noted that the inhibitory effect of BC mix on PLC/PRF/5 cell proliferation was greater than the sum of the inhibitory effects of Berberine and Costunolide. To evaluate the combined effects of Berberine and Costunolide on PLC/PRF/5 cells, we treated PLC/PRF/5 cells with different concentrations of BC mix. As shown in Fig 2D, the treatment with $\mathrm{BC}$ mix was more effective in inhibiting the proliferation of PLC/PRF/5 cells than the sum of the inhibitory effects of using Berberine or Costunolide alone. The results showed that the combination of Berberine and Costunolide has a synergistic effect on inhibiting the proliferation of hepatoma cells. Subsequently, we used the Calcusyn software program for median analysis. The median effect analysis was then performed using the Calcusyn software program. The effect of constant ratio of Berberine and Costunolide on the growth of the $\mathrm{PLC} / \mathrm{PRF} / 5$ cells was calculated. The data obtained in this study were analyzed by the ChouTalalay method, and the synergistic effects were analyzed by the combination index (CI). CI $<1,=1$, and $>1$ represent synergistic, additive, and antagonistic effects, respectively [30]. We found that four of the five $\mathrm{BC}$ mix concentrations used in this experiment had a combined index of less than $1(\mathrm{CI}<1)(\mathrm{Fig} 2 \mathrm{E})$, indicating that the Berberine and Costunolide have synergistic anti-tumor effects (Table 2). This synergistic effect brings the extra benefit of a combination of Coptidis Rhizoma and Aucklandia lappa Decne, which supports the value of DHW formula.

\section{DHW inhibits the proliferation of hepatoma cells by regulating EGF signaling pathway}

We set out to explore the potential mechanism by which DHW inhibits the proliferation of liver cancer cells. EGF signaling is a core signaling pathway that regulates cell proliferation. Overexpression of EGFR and its abnormal activity are closely related to the occurrence and development of various malignant tumors including liver cancer. Therefore, we first 
A.
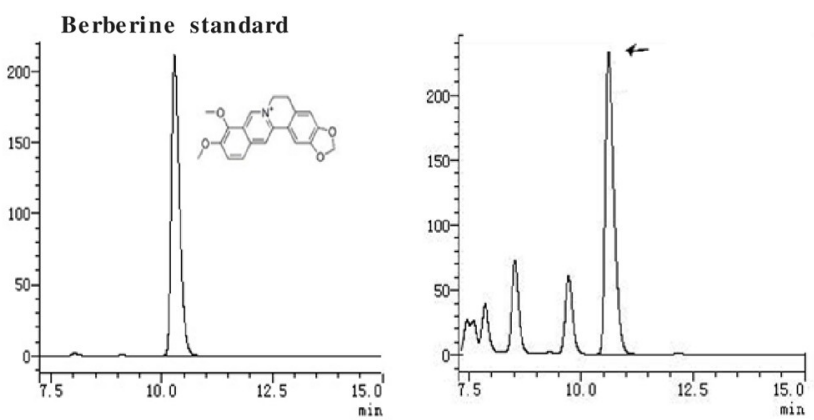

B.

Costunolide standard
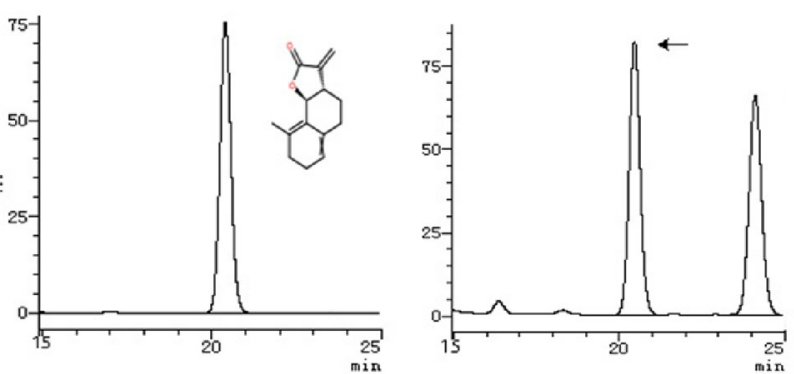

C.
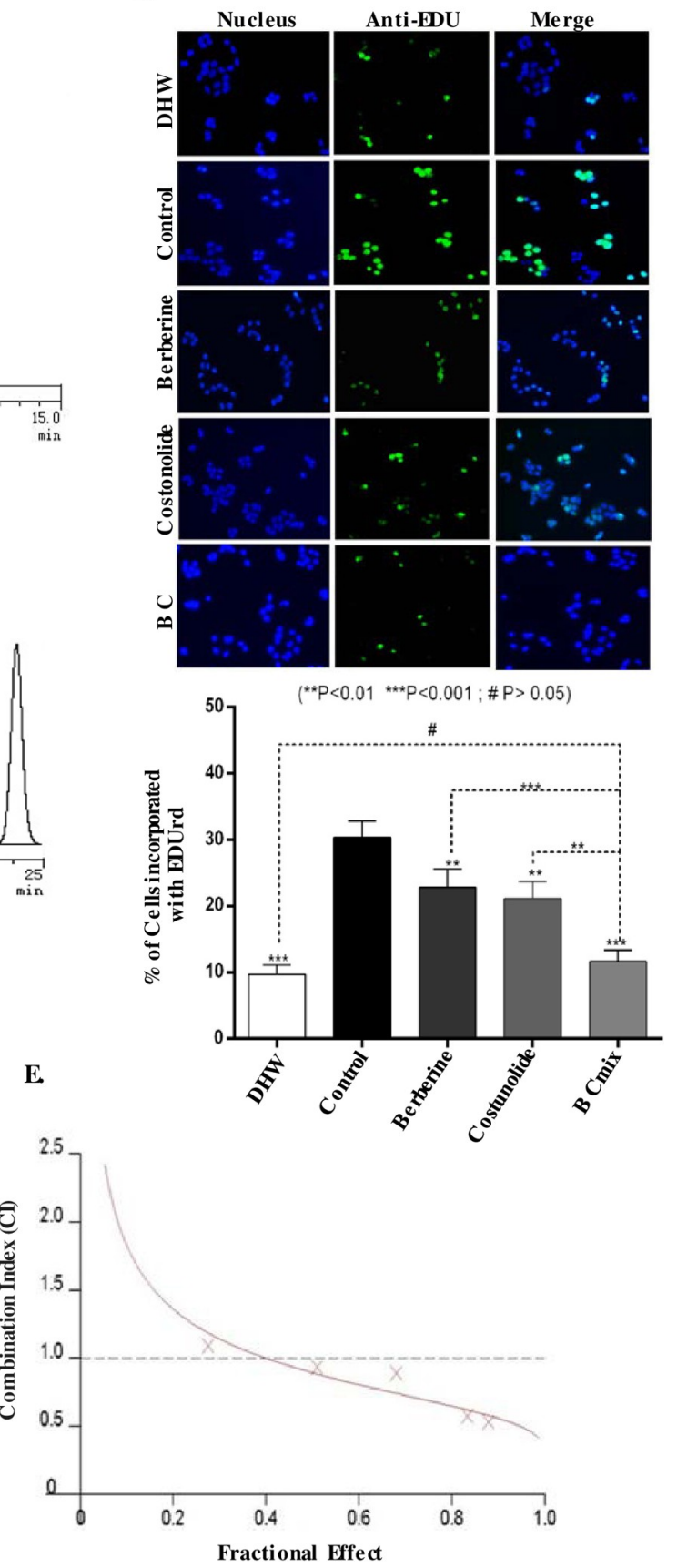

Fig 2. A, Panel 1 is the chromatogram and structure of Berberine standard; Panel 2 is the chromatogram of DHW samples; High performance liquid chromatograms. B, Panel 1 is the structure and chromatogram of Costunolide standard, Panel 2 is the chromatogram of DHW samples in different analysis. Arrows indicate the peaks representing Berberine or Costunolide; C, EdUrd incorporation assays were performed on PLC/PRF/ 5 cells treated with either DMSO (control), Berberine $(2.5 \mu \mathrm{g} / \mathrm{ml})$ and/or Costunolide $(0.5 \mu \mathrm{g} / \mathrm{ml})$, DHW extract $(40 \mu \mathrm{g} / \mathrm{ml})$. The percentage of cells incorporating EDUrd after 48 hrs was shown. D, PLC/PRF/5 cells were treated with Berberine (Ber) and Costunolide(Cos) or both (BC mix) in a fixed ratio (5:1) for 48 hrs. Cell viability was measured by MTT assay. E, CI was calculated by isobologram analysis using the Chou-Talalay method. $\mathrm{CI}=1$, additive effect; $\mathrm{CI}<1$, synergistic effect; CI, >1, antagonistic effect. Data represented are from three independent experiments.

https://doi.org/10.1371/journal.pone.0231466.g002 
Table 2. Synergistic effects of Berberine with Costunolide on growth of PLC/PRF/ 5 cells.

\begin{tabular}{c|c|c|c|c|}
\hline \multirow{2}{*}{ Dose $(\mu \mathrm{g} / \mathrm{mL})$} & \multicolumn{3}{|c|}{ Craction of Cells Affected (FA) } \\
\cline { 2 - 5 } & Berberine & Costunolide & 0.276 & \multicolumn{2}{c}{ BC mix } \\
\hline 2.5 & 0.168 & 0.153 & 0.509 & 0.095 \\
\hline 5.0 & 0.394 & 0.436 & 0.681 & 0.935 \\
\hline 10 & 0.405 & 0.449 & 0.834 & 0.895 \\
\hline 15 & 0.688 & 0.520 & 0.880 & 0.578 \\
\hline 20 & 0.778 & 0.531 & 0.533 \\
\hline
\end{tabular}

Abbreviations are as follows: FA, Fraction of cells with growth affectedin response to Berberine and /or Costunolide treated vs. uncreated cells; CI, combination Index. $\mathrm{CI}<1.0$ indicates synergism.

determined the expression and activation of EGFR in hepatoma cells such as PLC/PRF/5, HCC-LM3, HepG2, Hur7, SMMC-7721 cells. QSG-7701 human hepatocyte was used as controls. As shown in Fig 3A, both EGFR expression and phosphorylation were significantly increased in hepatoma cells compared to normal hepatocytes (Fig 3A, $1^{\text {st }}$ panel from top, lanes $1-5$, compared to lane 6). We further confirmed that EGF signaling is critical for the proliferation of liver cancer cells by EGFR inhibitor SC0186. PLC/PRF/5, LM3, HepG2, Hur7, SMMC7721 cells were cultured and then treated with $10 \mathrm{mM} \mathrm{SC} 0186$ for $24 \mathrm{hrs}$. The proliferation of these cells was inhibited by SC0186, and EGFR phosphorylation of these cells was also blocked (Fig 3B, $1^{\text {st }}$ panel from top, lane 1-5).

Since EGF signaling is critical for the proliferation of hepatoma cells, we then further explored whether DHW inhibits hepatoma cell proliferation by regulating EGF signaling. $\mathrm{PLC} / \mathrm{PRF} / 5$ cells were cultured and incubated with DHW extract, Berberine, Costunolide, or BC mix for 48 hrs. As shown in Fig 3, the expression and phosphorylation of EGFR were significantly reduced after treatment with DHW extract or BC mix (Fig 3C, $1^{\text {st }}$ Panel from top, lane 1 and 5 compared to lane 2; $2^{\text {nd }}$ Panel from top, lane 1 and 5 compared to lane 2). Examination on the activities of the downstream kinases of EGF signaling revealed that the Protein Kinase B (AKT) phosphorylation was remarkably inhibited, whereas Extracellular signal-regulated kinase (ERK) phosphorylation was up-regulated (Fig 3C, $1^{\text {st }}$ panel from top, lane 6 and 10 compared to lane 7; Fig 3C, $1^{\text {st }}$ panel from top, lane 11 and 15 compared to lane 12). We further confirmed this result with the EGFR inhibitor SC0186. Both DHW extract and the EGFR inhibitor SC0186 significantly inhibited the growth of hepatoma cells (Fig 3D). However, DHW extract alone and the combination of DHW extract and SC0186 have the similar inhibition on PLC/PRF/5 cell proliferation (Fig 3D). We believe that this is because DHW inhibits cell proliferation primarily through EGF signaling, and the use of the EGFR inhibitor SC0186 in combination with DHW does not provide additional benefits. Therefore, this result indicates that DHW inhibits hepatoma cell proliferation by modulating EGF signaling.

\section{Berberine and Costunolide promote the endocytosis and degradation of EGFR respectively}

EGF signaling is the core of cell proliferation and is always tightly controlled. Upon activated by extracellular signals, phosphorylated EGFR is endocytosed through either clathrin-dependent or clathrin-independent pathways [26]. When EGFR is endocytosed, it is then ubiquitinated and directed to lysosomes for degradation. There are also some EGFR that will be recycled back to the cell surface to participate in the new activation process. Endocytosis and degradation of EGFR shut down the activated EGF signaling, allowing for tight regulation of the EGF signaling pathway. In addition to, for example, mutation-induced 
A.

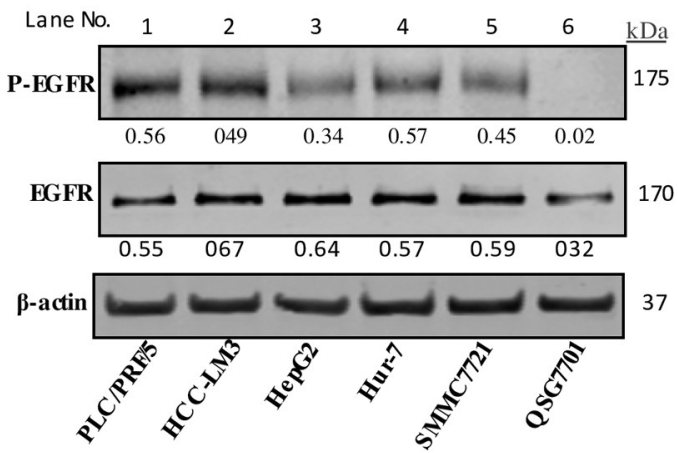

B.

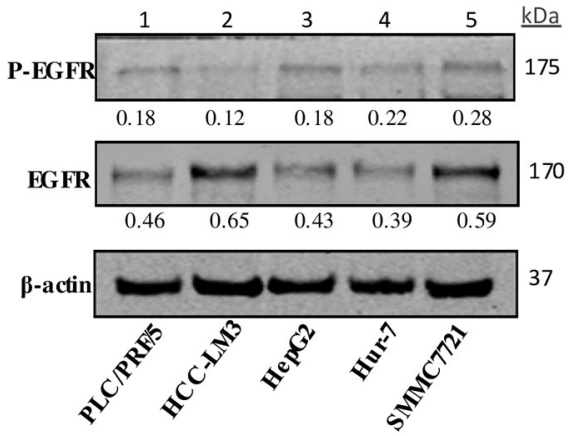

\section{C.}

PLC/PRF/5 Cells

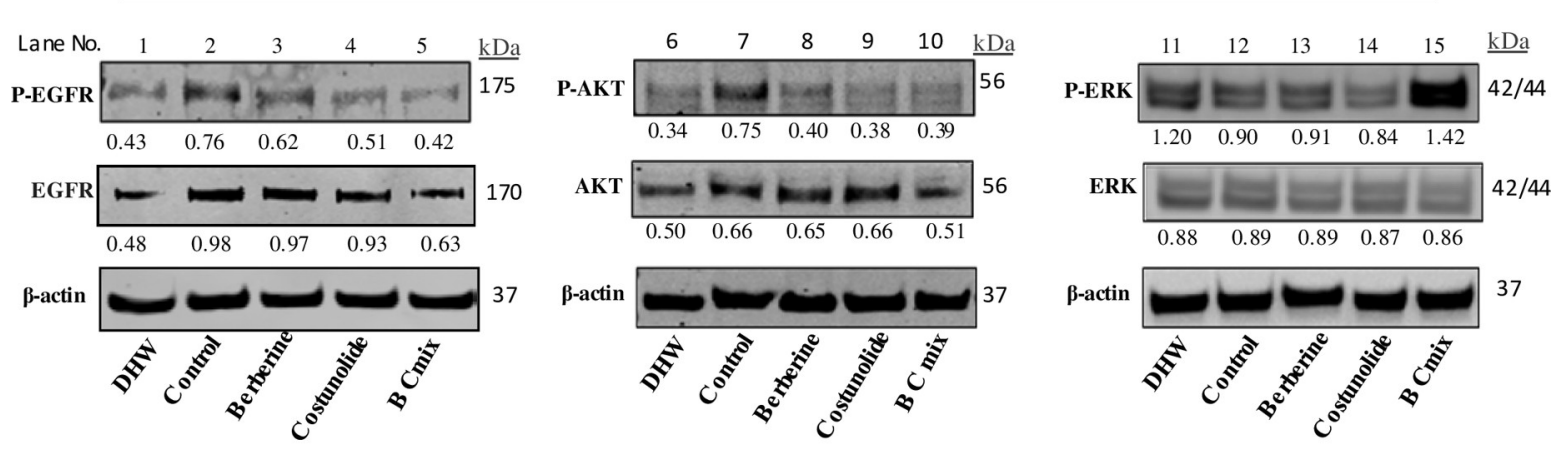

D.
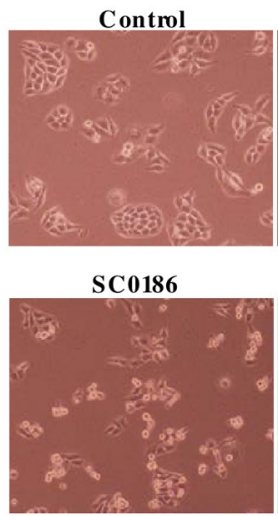

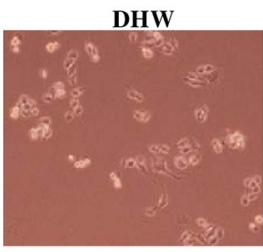

DHW +SC0186

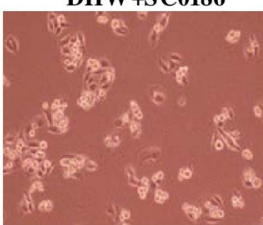

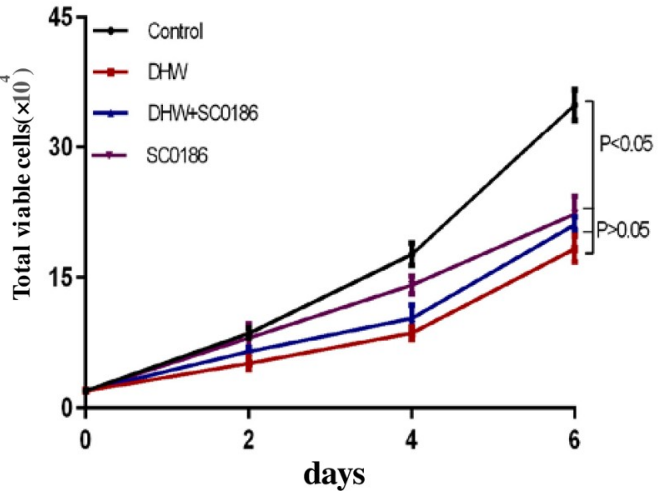

Fig 3. A, the expression and activation of EGFR in hepatoma cells such as PLC/PRF/5, HCC-LM3, HepG2, Hur7 and SMMC-7721 cells compared to normal hepatocytes; B, The EGFR and P-EGFR levels in HCC cells were examined by Western blot after treatment treated with $10 \mathrm{mM}$ SC0186 for $24 \mathrm{hrs}$; C, PLC/PRF/5 cells were treated with DHW extract, Berberine, Costunolide or BC mix at concentrations of $40 \mu \mathrm{g} /$ $\mathrm{ml}, 2.5 \mu \mathrm{g} / \mathrm{ml}$ and $0.5 \mu \mathrm{g} / \mathrm{ml}$ for $48 \mathrm{hrs}$, and then the expression levels of the relevant factors (EGFR, P-EGFR, Akt, P-Akt, ERK, P-ERK) were determined by Western blot; D, Effect of DHW extract, he EGFR inhibitor SC0186 and the combination of DHW extract and SC0186 on cellular growth and morphological changes of PLC/PRF/5 cells.

https://doi.org/10.1371/journal.pone.0231466.g003

hyperphosphorylation of EGFR, the abnormalities in EGFR signaling are more due to the disruption of the balance of EGFR endocytosis and degradation. 
In this study, we found that DHW inhibits hepatoma cell proliferation by blocking EGF signaling (Fig 3C). Therefore, we first examined whether Berberine and Costunolide inhibit EGF signaling by directly blocking EGFR phosphorylation. PLC/PFR/5 cells were serum-starved and incubated with Berberine, Costunolide, BC mix, or DHW extract for $24 \mathrm{hrs}$, and then stimulated by EGF $(10 \mathrm{ng} / \mathrm{ml})$ for 30 mins. As shown in Fig 3C, although both Berberine and Costunolide reduced EGFR phosphorylation in PLC/PFR/5 cells cultured in full serum (Fig $3 \mathrm{C}, 1^{\text {st }}$ panel from top, lane 3 and 4 compared to lane 2), but neither Berberine nor Costunolide blocked EGFR phosphorylation stimulated by EGF (Fig 4A, $1^{\text {st }}$ panel from top, lane 8 and 9 compared to lane 7). DHW extract or BC mix also failed to prevent EGF-stimulated EGFR phosphorylation (Fig 4A, $1^{\text {st }}$ panel from top, lane 6 and 10 compared to lane 7), while both inhibited EGFR phosphorylation in cells cultured in full serum (Fig 3C, $1^{\text {st }}$ panel from top, lane 1and 5 compared to lane 2). We also noticed that DHW extract treatment significantly reduced EGFR expression in cells cultured in full serum (Fig 3C, $2^{\text {nd }}$ Panel from top, lane 1 compared to lane 2). All of these results indicate that DHW or its major active ingredient, Berberine or Costunolide, does not directly target EGFR phosphorylation, but indirectly reduces EGF signaling over a longer period of time. Therefore, we suspect that Berberine or Costunolide might target the endocytosis and degradation processes of EGFR.

We set out to examine the effects of Berberine or Costunolide on the endocytosis and ubiquitination of EGFR. We used immunofluorescence to detect the presence of EGFR on the surface of PLC/PRF/5 cells. As shown in Fig 4B, Berberine, Costunolide, or BC mix attenuated the presence of EGFR on the surface of PLC/PRF/5 cells (Fig 4B, picture from left, picture 2-4 compared to picture 1). We then isolated cell surface EGFR using EZ-link Sulfo-NHS-SS-biotin. Costunolide and BC mix significantly reduced the amount of EGFR on the cell surface (Fig 4C, $1^{\text {st }}$ panel from top, lane6 and 8 compared to lane 5). The reduced cell surface EGFR may be due to a decrease of EGFR precursor transport resulting in reduced amount of cytoplasmic protein to the cell surface, or the accelerated endocytosis of EGFR from the cell surface. Therefore, we examined the effect of Berberine or Costunolide on the EGFR internalization after EGF stimulation. We first labeled the cell surface proteins with SulfoNHS-SS-biotin and then incubated these PLC/PRF/5 cells with Berberine, Costunolide, or BC mix as indicated. The biotin label of the cell surface proteins were then stripped with MesNa. Therefore, the signals we detected represent internalized cell surface proteins. As shown in Fig 4, after Berberine treatment, the internalization of cell surface EGFR was enhanced, while Costunolide had no significant effect on the internalization of EGFR (Fig 4C, $1^{\text {st }}$ panel from top, lane10 and lane11 compared to lane 9). This result indicates that Berberine promotes the internalization of EGFR. Subsequently, we evaluated EGFR ubiquitination in PLC/PRF/5 cells exposed to Berberine, Costunolide, BC mix via immunoprecipitation with anti-EGFR antibody followed by immunoblotting with an anti-ubiquitin antibody. We found that Costunolide and BC increased EGFR ubiquitination, while Berberine has a limited effect on EGFR ubiquitination (Fig 4D, $1^{\text {st }}$ panel from top, lane 2, 3 and 4 compared to lane 1). These results demonstrated that Berberine and Costunolide target different processes of EGFR degradation. Berberine promotes the internalization of EGFR while Costunolide can increase EGFR ubiquitination. This also explains why the combination of Berberine and Costunolide has a synergistic effect on EGF signaling, thereby providing DHW with an additional advantage of inhibiting cancer cell proliferation and treating cancer.

\section{Discussion}

DHW is a traditional herbal medicine used by Mongolians for many years. Although the underlying mechanisms are unclear, the drug does benefit cancer patients. For many 
A.

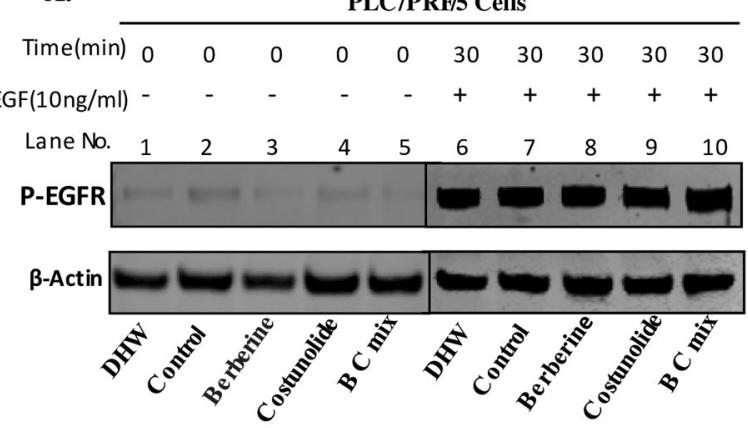

D.

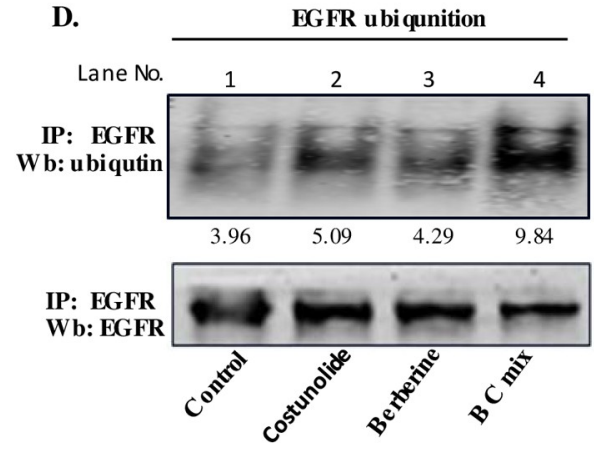

B.

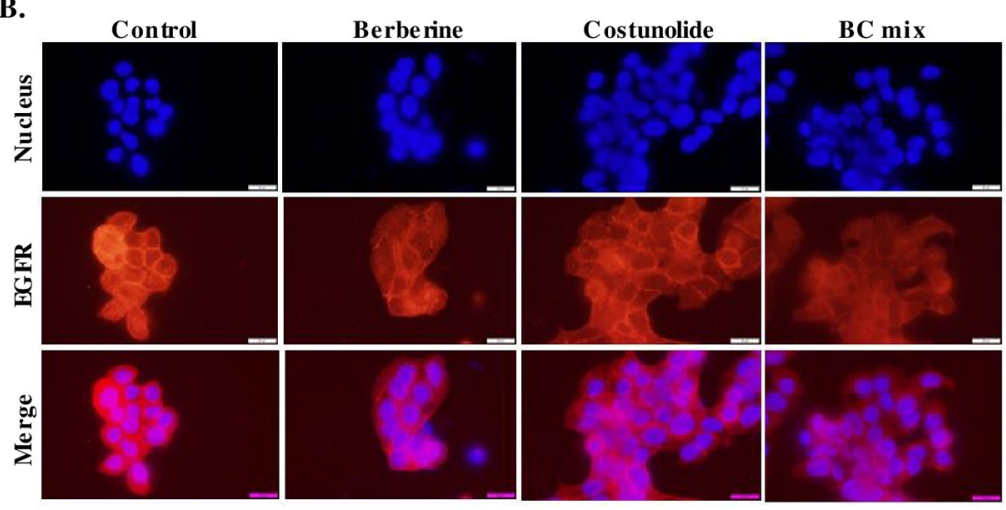

C.

Cell Surface Protein

\begin{tabular}{|c|c|c|c|c|c|c|c|c|}
\hline \multirow{2}{*}{$\begin{array}{l}\text { EGF(10ng/ml) } \\
\text { Lane No. }\end{array}$} & - & $\begin{array}{lll}- & -1 \\
\end{array}$ & $\begin{array}{l}- \\
-\end{array}$ & - & + & + & + & + \\
\hline & 1 & 2 & 3 & 4 & 5 & 6 & 7 & 8 \\
\hline \multirow[t]{2}{*}{ IP: EGFR } & 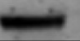 & - & $=$ & $=$ & 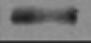 & 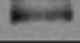 & $\longrightarrow$ & $\because$ \\
\hline & 0.74 & 0.67 & 0.70 & 0.52 & 0.63 & 0.44 & 0.51 & 0.39 \\
\hline
\end{tabular}
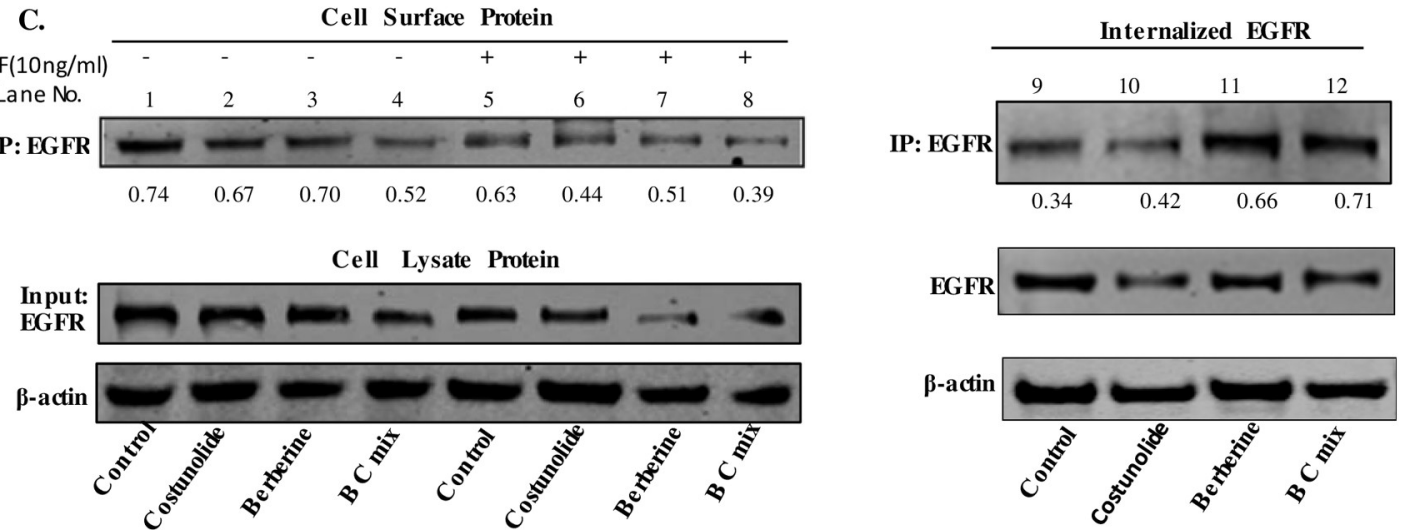

Fig 4. A, PLC/PFR/5 cells were serum-starved and incubated without (control) or with Berberine, Costunolide and BC mix for $24 \mathrm{hrs,}$ and then stimulated by EGF $(10 \mathrm{ng} / \mathrm{ml})$ for 30 mins. The expression level of P-EGFR in PLC/PRF/5 cells was examined by Western blot. B, EGFR on the surface of PLC/PRF/5 cells were examined by immunofluorescence after treated with Berberine, Costunolide and BC mix for $24 \mathrm{hrs}$, and then stimulated by EGF (10ng/ml) for 30 mins; C, PLC/PFR/5 cells were serum-starved and incubated without (control) or with Berberine, Costunolide, and BC mix for $24 \mathrm{hrs}$, and then stimulated by EGF (10ng/ml) for 30 mins. Proteins on cell surface were labeled with Sulfo-NHS-SS-Biotin and isolated by streptavidin and then analyzed by immunoblot detected EGFR (lane58); The internalized cell surface proteins were isolated using Sulfo-NHS-SS-Biotin and MesNa and analyzed by immunoblot detecting EGFR (top panel) (lane9-12). D, PLC/PRF/5 cells were incubated without (control) or with Berberine, Costunolide, and BC mix for the indicated time periods. Ubiquitinated EGFR was examined via EGFR immunoprecipitation followed by immunoblotting with an ubiquitin antibody. The bands were quantified. The level of ubiquitinated EGFR was normalized to the immunoprecipitated EGFR. The relative density of the control. 
traditional herbal medicines, the situation is similar: there are no well-controlled scientific experiments to verify the validity of these drugs, and there are no clues about their underlying mechanisms and side effects, which greatly limits clinical applications and further optimization of these drugs. In this study, we first demonstrated that DHW inhibits the proliferation of hepatoma cells by modulating EGF signaling. Berberine and Costunolide are the main active ingredients in DHW. Berberine promotes endocytosis of activated EGFR, while Costunolide increases ubiquitination of EGFR and reduces the distribution of EGFR on the cell membrane, thereby inhibiting the activation of EGF signaling. Berberine and Costunolide target different processes of EGFR degradation, resulting in a significant synergistic effect in inhibiting cell proliferation. This is the benefit of a combination of Berberine and Costunolide in the DHW formula. In addition, neither Berberine nor Costunolide directly target EGFR phosphorylation. This allows DHW to be used as a supplementary medicine to tyrosine kinase inhibitors in cancer therapy.

EGF signaling is a key signaling pathway that regulates cell proliferation. Extracellular signal molecules stimulate EGFR phosphorylation and then trigger this signal cascade. Phosphorylation of EGFR also initiates the internalization of EGFR, thereby shutting down the EGF signaling. Phosphorylated EGFR will then be ubiquitinated and engulfed by primary endocytosis, transforming from a membrane distribution to an intracytoplasmic vesicle distribution. Primary endocytic vesicles grow into secondary vesicles and bind to lysosomes, and the ubiquitin-protease system can be activated to degrade EGFR [24,31]. We found that both Berberine and Costunolide target and facilitate the EGFR internalization and degradation system. The synergistic effect of the combination of Berberine and Costunolide suggests that they target different EGFR internalization and degradation processes. We further demonstrate that Berberine promotes endocytosis of activated EGFR, while Costunolide increases ubiquitination of EGFR. However, the exactly targets of Berberine and Costunolide remain unclear. To identify these targets and underlying mechanisms, further experiments are necessary in the future.

In this study, we focused on the effects of Berberine and Costunolide on EGF signaling. As natural compounds, Berberine and Costunolide may target other signaling cascades. Previous studies have shown that Berberine prevents secretion of VEGF from HCC and down-regulating VEGF mRNA expression [32]. Costunolide also inhibits proliferation and survival of colorectal cancer cells via inhibiting Wnt/ $\beta$-Catenin signaling pathway [33]. Although we cannot rule out the possibility of Berberine and Costunolide targeting other signaling pathways, we did demonstrate in this study that in certain tumor cells, like PLC/PRF/5, HT29, and HCC-LM3, Berberine and Costunolide inhibit tumor cell proliferation by modulating EGF signaling.

DHW is a traditional herbal medicine. In this study, we determined that Berberine and Costunolide are the main active components in DHW. This does not exclude the presence of other active ingredients in the DHW. In fact, Coptidis Rhizoma is composed of various alkaloids, including Berberine, coptisine, palmatine, and jatrorrhizine. Aucklandia lappa Decne root extract contains resinoids, essential oil, alkaloid, inulin, a fixed oil, and other minor ingredients such as tannins and sugars [12]. In this study, we found that BC mix and DHW extract have similar inhibitory effects on PLC/PRF/5 cell proliferation (Fig 2C). They inhibited PLC/ PRF/5 cells better than either Berberine or Costunolide alone (Fig 2D). Therefore, at least for certain liver cancer cell such as PLC/PRF/5 cells, Berberine and Costunolide are indeed the main anti-cancer active ingredients of DHW.

As summarized in Fig 5, our study indicates that Berberine and Costunolide are key active ingredients for inhibiting the growth of hepatoma cell by DHW extract in vitro. Berberine and Costunolide target different steps of EGFR internalization and degradation, and mutually 


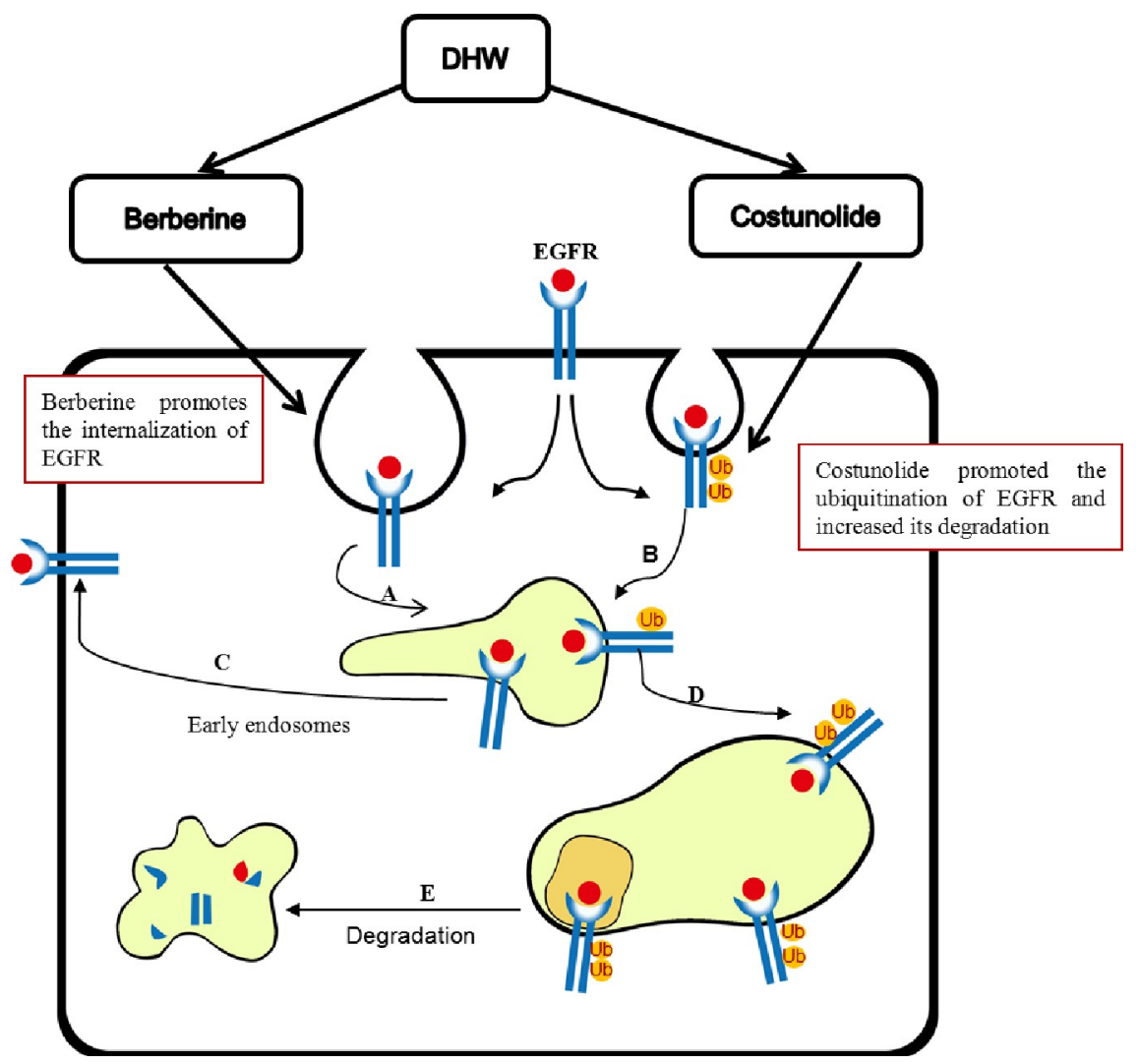

Fig 5. A model for the function of DHW in EGFR homeostasis. Berberine and Costunolide are the main active ingredients in DHW. Berberine promotes endocytosis of activated EGFR, while as Costunolide increases ubiquitination of EGFR and reduces EGFR recycling to cell membrane distribution, thereby inhibiting EGF signaling. Part of internalized EGFR goes into early endosomes (A). Following their internalization into early endosomes, nonubiquitinated receptors are recycled back to the plasma membrane (C). Part of internalized EGFR is ubiquitinated (B). Ubiquitinated EGFRs proceed toward the multivesicular bodies (D). Ubiquitinated cargo pour into lysosomes for degradation (E).

https://doi.org/10.1371/journal.pone.0231466.g005

enhance the inhibition on EGF signaling, resulting in a synergistic anti-cancer effect (Fig 5). These results suggest that the combination of Berberine and Costunolide is a potential antitumor drug for the treatment of liver cancer, and also provides a new understanding of the mechanism of action of traditional Mongolian medicines.

\section{Supporting information}

S1 File.

(PDF)

\section{Acknowledgments}

We acknowledge members of the Hongyang laboratory for critically reading the manuscript.

\section{Author Contributions}

Conceptualization: Ba Genna, B. Burenbatu, Qiyu Feng, Hongyang Wang.

Data curation: Ha Si. 
Formal analysis: $\mathrm{Ha} \mathrm{Si}$, Qiyu Feng.

Funding acquisition: $\mathrm{Ha} \mathrm{Si}, \mathrm{Ba}$ Genna, Qiyu Feng, Hongyang Wang.

Investigation: $\mathrm{Ha} \mathrm{Si}$, Xiangjin Zhuang.

Methodology: Qiyu Feng.

Project administration: Qiyu Feng.

Resources: Ha Si, B. Burenbatu, Qiyu Feng, Hongyang Wang.

Software: $\mathrm{Ha} \mathrm{Si}$, Jing Wang.

Supervision: Ba Genna, Qiyu Feng, Hongyang Wang.

Validation: Xiangjin Zhuang, Jing Wang.

Writing - original draft: $\mathrm{Ha} \mathrm{Si}$.

Writing - review \& editing: Ha Si, Qiyu Feng.

\section{References}

1. Bray F, Ferlay J, Soerjomataram I, Siegel RL, Torre LA, et al. (2018) Global cancer statistics 2018: GLOBOCAN estimates of incidence and mortality worldwide for 36 cancers in 185 countries. CA Cancer J Clin 68: 394-424. https://doi.org/10.3322/caac.21492 PMID: 30207593

2. Llovet JM, Villanueva A, Lachenmayer A, Finn RS (2015) Advances in targeted therapies for hepatocelIular carcinoma in the genomic era. Nat Rev Clin Oncol 12: 408-424. https://doi.org/10.1038/nrclinonc. 2015.103 PMID: 26054909

3. HanZhiqiang HS (2017) Study on the Optimum Extraction Technology for Mongolian Medicine Runing Granules Traditional Medical Science and Tecnology 24: 46-48.

4. Yang WJ, Li DP, Li JK, Li MH, Chen YL, et al. (2009) Synergistic antioxidant activities of eight traditional Chinese herb pairs. Biol Pharm Bull 32: 1021-1026. https://doi.org/10.1248/bpb.32.1021 PMID: 19483308

5. Tang J, Feng Y, Tsao S, Wang N, Curtain R, et al. (2009) Berberine and Coptidis rhizoma as novel antineoplastic agents: a review of traditional use and biomedical investigations. J Ethnopharmacol 126: 517. https://doi.org/10.1016/j.jep.2009.08.009 PMID: 19686830

6. Wang N, Feng Y, Lau EP, Tsang C, Ching Y, et al. (2010) F-actin reorganization and inactivation of rho signaling pathway involved in the inhibitory effect of Coptidis Rhizoma on hepatoma cell migration. Integr Cancer Ther 9: 354-364. https://doi.org/10.1177/1534735410379121 PMID: 21106616

7. Hou Q, Tang X, Liu H, Tang J, Yang Y, et al. (2011) Berberine induces cell death in human hepatoma cells in vitro by downregulating CD147. Cancer Sci 102: 1287-1292. https://doi.org/10.1111/j.13497006.2011.01933.x PMID: 21443647

8. Yoshikawa M, Hatakeyama S, Inoue Y, Yamahara J (1993) Saussureamines A, B, C, D, and E, new anti-ulcer principles from Chinese Saussureae Radix. Chem Pharm Bull (Tokyo) 41: 214-216.

9. Choi JY, Na M, Hyun Hwang I, Ho Lee S, Young Bae E, et al. (2009) Isolation of betulinic acid, its methyl ester and guaiane sesquiterpenoids with protein tyrosine phosphatase 1B inhibitory activity from the roots of Saussurea lappa C.B.Clarke. Molecules 14:266-272. https://doi.org/10.3390/ molecules14010266 PMID: 19136914

10. Hasson SS, AS HA-S, Al-Busaidi JZ, Al-Balushi MS, Hakkim FL, et al. (2018) Potential of Aucklandia Lappa Decne Ethanolic Extract to Trigger Apoptosis of Human T47D and Hela Cells. Asian Pac J Cancer Prev 19: 1917-1925. https://doi.org/10.22034/APJCP.2018.19.7.1917 PMID: 30051673

11. Tian X, Song HS, Cho YM, Park B, Song YJ, et al. (2017) Anticancer effect of Saussurea lappa extract via dual control of apoptosis and autophagy in prostate cancer cells. Medicine (Baltimore) 96: 30 (e7606).

12. Moon SM, Yun SJ, Kook JK, Kim HJ, Choi MS, et al. (2013) Anticancer activity of Saussurea lappa extract by apoptotic pathway in KB human oral cancer cells. Pharm Biol 51: 1372-1377. https://doi.org/ 10.3109/13880209.2013.792847 PMID: 23855888

13. Seo CS, Lim HS, Jeong SJ, Shin HK (2015) Anti-allergic effects of sesquiterpene lactones from the root of Aucklandia lappa Decne. Mol Med Rep 12: 7789-7795. https://doi.org/10.3892/mmr.2015.4342 PMID: 26398906 
14. Singireesu S, Misra S, Mondal SK, Yerramsetty S, Sahu N, et al. (2018) Costunolide induces micronuclei formation, chromosomal aberrations, cytostasis, and mitochondrial-mediated apoptosis in Chinese hamster ovary cells. Cell Biol Toxicol 34: 125-142. https://doi.org/10.1007/s10565-017-9411-z PMID: 28914393

15. Wang Z, Zhao X, Gong X (2016) Costunolide induces lung adenocarcinoma cell line A549 cells apoptosis through ROS (reactive oxygen species)-mediated endoplasmic reticulum stress. Cell Biol Int 40 : 289-297. https://doi.org/10.1002/cbin.10564 PMID: 26609913

16. Hua P, Zhang G, Zhang Y, Sun M, Cui R, et al. (2016) Costunolide induces G1/S phase arrest and activates mitochondrial-mediated apoptotic pathways in SK-MES 1 human lung squamous carcinoma cells. Oncol Lett 11: 2780-2786. https://doi.org/10.3892/ol.2016.4295 PMID: 27073552

17. Hua $P$, Sun M, Zhang G, Zhang Y, Song G, et al. (2016) Costunolide Induces Apoptosis through Generation of ROS and Activation of P53 in Human Esophageal Cancer Eca-109 Cells. J Biochem Mol Toxicol 30: 462-469. https://doi.org/10.1002/jbt.21810 PMID: 27078502

18. Yang YI, Kim JH, Lee KT, Choi JH (2011) Costunolide induces apoptosis in platinum-resistant human ovarian cancer cells by generating reactive oxygen species. Gynecol Oncol 123: 588-596. https://doi. org/10.1016/j.ygyno.2011.08.031 PMID: 21945308

19. Kim JH, Yang YI, Lee KT, Park HJ, Choi JH (2011) Costunolide induces apoptosis in human endometriotic cells through inhibition of the prosurvival Akt and nuclear factor kappa B signaling pathway. Biol Pharm Bull 34: 580-585. https://doi.org/10.1248/bpb.34.580 PMID: 21467650

20. Lemmon MA, Schlessinger J (2010) Cell signaling by receptor tyrosine kinases. Cell 141: 1117-1134. https://doi.org/10.1016/j.cell.2010.06.011 PMID: 20602996

21. Normanno N, De Luca A, Bianco C, Strizzi L, Mancino M, et al. (2006) Epidermal growth factor receptor (EGFR) signaling in cancer. Gene 366: 2-16. https://doi.org/10.1016/j.gene.2005.10.018 PMID: 16377102

22. Seshacharyulu P, Ponnusamy MP, Haridas D, Jain M, Ganti AK, et al. (2012) Targeting the EGFR signaling pathway in cancer therapy. Expert Opin Ther Targets 16: 15-31. https://doi.org/10.1517/ 14728222.2011.648617 PMID: 22239438

23. Miyamoto $\mathrm{Y}$, Suyama K, Baba H (2017) Recent Advances in Targeting the EGFR Signaling Pathway for the Treatment of Metastatic Colorectal Cancer. Int J Mol Sci 18: 752-15.

24. Hou Y, Zhou M, Xie J, Chao P, Feng Q, et al. (2017) High glucose levels promote the proliferation of breast cancer cells through GTPases. Breast Cancer (Dove Med Press) 9: 429-436.

25. Conte A, Sigismund S (2017) Methods to Investigate EGFR Ubiquitination. Methods Mol Biol 1652: 81-100. https://doi.org/10.1007/978-1-4939-7219-7_5 PMID: 28791635

26. Conte A, Sigismund S (2016) Chapter Six-The Ubiquitin Network in the Control of EGFR Endocytosis and Signaling. Prog Mol Biol TransI Sci 141:225-276. https://doi.org/10.1016/bs.pmbts.2016.03.002 PMID: 27378759

27. Lei CT, Wei YH, Tang H, Wen Q, Ye C, et al. (2017) PKC-alpha Triggers EGFR Ubiquitination, Endocytosis and ERK Activation in Podocytes Stimulated with High Glucose. Cell Physiol Biochem 42: 281294. https://doi.org/10.1159/000477329 PMID: 28535513

28. Pinilla-Macua I, Sorkin A (2015) Methods to study endocytic trafficking of the EGF receptor. Methods Cell Biol 130: 347-367. https://doi.org/10.1016/bs.mcb.2015.05.008 PMID: 26360045

29. N.P C (2015) PharmacopoeiaPeople's Repub.China.: 64-303.

30. Chou TC (2010) Drug combination studies and their synergy quantification using the Chou-Talalay method. Cancer Res 70: 440-446. https://doi.org/10.1158/0008-5472.CAN-09-1947 PMID: 20068163

31. Miyamoto $\mathrm{Y}$, Suyama K, Baba H (2017) Recent Advances in Targeting the EGFR Signaling Pathway for the Treatment of Metastatic Colorectal Cancer. Int J Mol Sci 18: 15.

32. Jie S, Li H, Tian Y, Guo D, Zhu J, et al. (2011) Berberine inhibits angiogenic potential of Hep G2 cell line through VEGF down-regulation in vitro. J Gastroenterol Hepatol 26: 179-185. https://doi.org/10.1111/j. 1440-1746.2010.06389.x PMID: 21175812

33. Dong GZ, Shim AR, Hyeon JS, Lee HJ, Ryu JH (2015) Inhibition of Wnt/beta-Catenin Pathway by Dehydrocostus Lactone and Costunolide in Colon Cancer Cells. Phytother Res 29: 680-686. https://doi.org/ 10.1002/ptr.5299 PMID: 25625870 